\title{
The prevalence and correlates of common mental disorders among prisoners in Addis Ababa: an institution based cross-sectional study
}

\author{
Alemseged Solomon ${ }^{1}$, Getnet Mihretie ${ }^{2}$ and Getachew Tesfaw ${ }^{2 *}$
}

\begin{abstract}
Objective: About one in seven prisoners is diagnosed with common mental disorders whose global prevalence ranges from 13 to 92.5\%. The problem negatively affects the physical, psychological, and social well-being of prisoners. However, research into common mental disorders and associated factors among prisoners in low and middleincome countries has been limited. Therefore, this study aimed to explore the common mental disorders and associated factors among prisoners in Ethiopia to contribute the attempt to ensure optimal care for prisoners.

Results: The prevalence of common mental disorders among prisoners was found to be $58.4 \%$ [95\% Cl 53.70, 63.00]. In the multivariable logistic regression, poor social support $[\mathrm{AOR}=2.4,95 \% \mathrm{Cl} 1.16,4.85]$, economic crisis $[\mathrm{AOR}=3$, $95 \% \mathrm{Cl} 1.84,4.85]$, secondary school education $[\mathrm{AOR}=2.3,95 \% \mathrm{Cl} 1.04,5.20]$, unemployment before arrest $[\mathrm{AOR}=1.7$, $95 \% \mathrm{Cl} 1.04,2.80]$, and history of psychiatric illness [AOR $=4.3,95 \% \mathrm{Cl} 1.21,15.56$ ] were factors significantly associated with the problem.
\end{abstract}

Keywords: Common mental disorder, Prisoner, Correctional Institution

\section{Introduction}

Common mental disorder (CMD) is a term used to describe a group of mental disorders that frequently include depression, anxiety, and somatoform which are highly prevalent in low and middle-income countries [13]. According to estimation, over 450 million people in the world suffer from some form of mental disorder and one in four whom met the criteria in their lives have had mental disorders $[1,4]$.

The prevalence of the CMD which is $14 \%$ today, is predicted will rise to $15 \%$ by 2020 , becoming the second leading cause of ill health in low-income countries [5, 6]. Over 10.2 million people held in penal institutions with restricted freedom, autonomy, and communication with their families have their physical, psychological, and

\footnotetext{
*Correspondence: getachewtesfaw@gmail.com

2 Department of Psychiatry, College of Medicine and Health Sciences, University of Gondar, Gondar, Ethiopia

Full list of author information is available at the end of the article
}

social well-being affected throughout the world [6, 7]. The magnitude of CMD is higher among prisoners than in the general public [8-10]. Common mental disorders which may be present before arrest might be further aggravated after imprisonment $[3,6]$.

Many prisoners, at least one CMD and nearly one in seven of those have such history, suffering from CMDs $[11,12]$. The overall magnitude, of CMD among prisoners ranges from 13 to $92.5 \%$ [11, 13]. In addition to imprisonment, the variety of other factors, like the prison environment, educational status, overcrowding, crime type, term of sentence and isolation from social networks have roles in the development of CMDs $[1,6,8,14]$.

Evidence suggests that the presence of mental illness among prisoners contributes to an increased in the risk of suicide, violence, morbidity, and mortality [1, 10, 12]. Prisoners who have psychiatric disorders need to have access to mental health treatment and support at all stages of criminal justice [15]. Timely identification, treatment, and rehabilitation are almost missing in many 
prisons, particularly in developing countries [6]. However, research into common mental disorders and associated factors among prisoners in low and middle-income countries is limited. Therefore, this study aimed to assess the prevalence and associated factors of common mental disorders among prisoners in the correctional institution in Ethiopia with a view of informing the development of interventions.

\section{Main text \\ Methods}

\section{Study setting and design}

An institution-based cross-sectional study was conducted at Addis Ababa correctional centers from May to June 2015, Addis Ababa, Ethiopia.

\section{Study population}

All sampled prisoners with jailed at Addis Ababa correctional centers were excluded. Prisoners critically ill were excluded.

\section{Sampling procedures}

The sample size was determined by using the single population proportion formula with the assumptions of $35.5 \%$ prevalence of CMD from a study conducted in Southwest Ethiopia, Jimma [16], with 95\% CI, and a $4 \%$ margin of error. Assuming a $10 \%$ non-response rate, 452 prisoners were recruited randomly by using the systematic sampling technique. The sampling interval was determined by dividing the total study population by the total sample size; then, the starting point was randomly selected.

\section{Data collection}

Data were collected using a pre-tested, intervieweradministered questionnaire which contained CMD, socio-demographic characteristics, clinical, and prisonrelated factors. We used a face to face interviewer administered questionnaire to collect data. Common mental disorders were measured by using Self Reporting Questionnaires-20 (SRQ-20), developed by the World Health Organization to screen CMD in primary health care settings in low-income countries [17]. However, owing to high illiteracy rate in Ethiopia and other countries of the same status, the tool was used in an interview format, validated and subsequently used for epidemiological, clinical and community settings in the country. The scales used as cutoff scores for CMD were $\geq 8$ [17].

Social support was assessed by the Oslo 3 -item social support scale which had a 3-item questionnaire commonly used to assess social support and used in several studies. The sum score scale ranges from 3 to 14 with three broad categories: "poor support" 3-8, "moderate support" 9-11, and "strong support" 12-14 [18].

Data were entered into Epi-info 7 software after checking for completeness and transferred to the statistical package for social sciences version 20 for analysis. Bi-variable and multivariable logistic regression analyses were done to see the association of each independent variable with the outcome variable. The strength of the association was evaluated using the adjusted odds ratio with a 95\% CI, and less than 0.05 P-values were considered statistically significant.

\section{Results}

\section{Socio-demographic characteristics}

A total of 452 respondents took part with a response rate off $98.9 \%$. The mean age of the respondents was $26( \pm 10)$ years; almost half (50.1\%) were female, 171 (38.3\%) were single, and $303(67.8 \%)$ were between the ages of 18 and 27 years (Table 1$)$.

\section{Psychosocial characteristics}

Of the participants, $48.8 \%$ had poor social support; only 65 (14.5\%) had chronic physical illnesses; 29 (6.5\%) were diagnosed with psychiatric illnesses, and 23 (5.1\%) were convicted once (Table 2).

\begin{tabular}{|c|c|c|c|}
\hline Variables & Categories & Frequency & Percent \\
\hline \multirow[t]{2}{*}{ Sex } & Male & 223 & 49.9 \\
\hline & Female & 224 & 50.1 \\
\hline \multirow[t]{5}{*}{ Age in years } & $18-27$ & 303 & 67.8 \\
\hline & $28-37$ & 83 & 18.6 \\
\hline & $38-47$ & 40 & 8.9 \\
\hline & $48-57$ & 15 & 3.3 \\
\hline & $\geq 58$ & 6 & 1.5 \\
\hline \multirow[t]{3}{*}{ Marital status } & Single & 301 & 67.3 \\
\hline & Married & 98 & 21.9 \\
\hline & Others $^{a}$ & 48 & 10.8 \\
\hline \multirow[t]{4}{*}{ Religions } & Orthodox & 334 & 74.7 \\
\hline & Muslim & 56 & 12.5 \\
\hline & Protestant & 49 & 11.0 \\
\hline & Others $^{b}$ & 8 & 1.8 \\
\hline \multirow[t]{4}{*}{ Ethnicity } & Amhara & 206 & 46.1 \\
\hline & Oromo & 95 & 21.1 \\
\hline & Tigray & 84 & 18.9 \\
\hline & Others $^{c}$ & 64 & 13.9 \\
\hline
\end{tabular}

\footnotetext{
a Divorce, widowed

b Jobba, Catholic

c Gurage, afar, and Somali
} 
Table 2 Distribution of psychosocial factors of prisoners at Addis Ababa correction center, Addis Ababa, Ethiopia, in $2015(n=447)$

\begin{tabular}{|c|c|c|c|}
\hline Variables & Categories & Frequency & Percent \\
\hline \multirow[t]{3}{*}{ Social support } & Poor & 218 & 48.8 \\
\hline & Moderate & 162 & 36.2 \\
\hline & Strong & 67 & 15.0 \\
\hline \multirow[t]{2}{*}{ Having a chronic physical disease } & Yes & 65 & 14.5 \\
\hline & No & 382 & 85.5 \\
\hline \multirow[t]{2}{*}{ Seriously illness, injury or assault of a prisoner in last 6 months } & Yes & 93 & 21.0 \\
\hline & No & 353 & 79.0 \\
\hline \multirow[t]{2}{*}{ Death of relative in the last 6 months } & Yes & 37 & 8.3 \\
\hline & No & 410 & 91.7 \\
\hline \multirow[t]{2}{*}{ Break up of friendship or relationship in the last 6 months } & Yes & 77 & 17.2 \\
\hline & No & 370 & 82.8 \\
\hline \multirow[t]{2}{*}{ The financial crisis in the last 6 months } & Yes & 268 & 60.0 \\
\hline & No & 179 & 40.0 \\
\hline \multirow[t]{2}{*}{ Ever diagnosis psychiatric illness } & Yes & 29 & 6.5 \\
\hline & No & 418 & 93.5 \\
\hline \multirow[t]{2}{*}{ A family history of mental illness } & Yes & 38 & 8.5 \\
\hline & No & 409 & 91.5 \\
\hline \multirow[t]{2}{*}{ Problem with police/court in the last 6 months } & Yes & 73 & 16.3 \\
\hline & No & 374 & 83.7 \\
\hline \multirow[t]{2}{*}{ No job before arrested } & Yes & 204 & 45.6 \\
\hline & No & 243 & 54.4 \\
\hline \multirow[t]{2}{*}{ Suffered from violence in the last 6 months } & Yes & 63 & 14.1 \\
\hline & No & 384 & 85.9 \\
\hline \multirow[t]{2}{*}{ Ever convicted } & Yes & 29 & 6.5 \\
\hline & No & 418 & 93.5 \\
\hline \multirow[t]{3}{*}{ How often do you convict } & Once & 23 & 5.1 \\
\hline & Twice & 2 & 0.4 \\
\hline & $\geq 3$ times & 3 & 0.7 \\
\hline
\end{tabular}

\section{Prisoner characteristics}

More than half $(55 \%)$ of the study participants were accused of shoplifting, and for 233 (52.1\%) the length of sentences were from 1 to 3 years duration. Over two in five (43.2\%) have stayed in prison for 1 to 3 years (Additional file 1).

\section{Prevalence of CMD among prisoners}

This study revealed that the prevalence of CMD among the study participants was found to be $58.4 \%$ with $95 \%$ CI $(53.7,63.0)$ (Additional file 2).

\section{Factors associated with CMD}

Among all explanatory variables, poor social support, educational status, history of psychiatric illness, and economic crisis had less than $0.2 P$ value in the bi-variable logistic regression considered as the multivariate logistic regression model.

The multivariate analysis suggested that poor social support was about 2.4 times more risky for CMD compared to patients with good social support (95\% CI $1.16,4.85)$. Economic crises in the last 6 months was 3.95 times $(95 \%$ CI $1.84,4.85)$ more likely to lead to CMDs compared to its absence.

Similarly, secondary school education was two times $(95 \%$ CI $1.04,5.20)$ more likely to lead to CMD compared to tertiary level of graduates, and the odds of CMD increased by 1.7 times (95\% CI 1.04, 2.80) for participants who had no jobs before arrest compared their counterparts. The odds of developing CMD were 4.3 times (95\% CI 1.21, 15.56) higher among participants who had history of mental illness compared with those who had such no history (Table 3). 
Table 3 Factors associated with common mental disorders among prisoners in Addis Ababa correctional center, Addis Ababa, Ethiopia, in 2015. $(n=447)$

\begin{tabular}{|c|c|c|c|c|c|}
\hline \multirow[t]{2}{*}{ Variables } & \multirow[t]{2}{*}{ Categories } & \multicolumn{2}{|c|}{ Common mental disorder } & \multirow[t]{2}{*}{ COR, 95\% (Cl) } & \multirow[t]{2}{*}{ AOR, 95\% (CI) } \\
\hline & & Yes & No & & \\
\hline \multirow[t]{4}{*}{ Level of educational } & Illiterate & 37 & 17 & $2.96(1.37,6.41)$ & $2.34(0.87-6.32)$ \\
\hline & Primary & 116 & 89 & $1.78(0.99,3.18)$ & $1.5(0.70-3.38)$ \\
\hline & Secondary & 83 & 46 & $2.45(1.31,4.61)$ & $2.3(1.04,5.20)^{*}$ \\
\hline & Above tertiary & 25 & 34 & $1: 00$ & $1: 00$ \\
\hline \multirow[t]{3}{*}{ Social support } & Poor & 147 & 71 & $3.1(1.74,5.40)$ & $2.4(1.16,4.85)^{* *}$ \\
\hline & Moderate & 87 & 75 & $1.72(0.96,3.10)$ & $1.8(0.80-3.17)$ \\
\hline & Strong & 27 & 40 & $1: 00$ & $1: 00$ \\
\hline \multirow[t]{2}{*}{ Financial crisis } & No & 67 & 112 & $1: 00$ & $1: 00$ \\
\hline & Yes & 194 & 74 & $4.4(3.00,6.57)$ & $3(1.84,4.85)^{* * *}$ \\
\hline \multirow[t]{2}{*}{ Job before arrested } & Yes & 117 & 126 & $1: 00$ & $1: 00$ \\
\hline & No & 144 & 60 & $2.6(1.75,3.83)$ & $1.7(1.04,2.80)^{*}$ \\
\hline \multirow[t]{2}{*}{ Ever diagnosed psychiatric illness } & No & 236 & 182 & $1: 00$ & $1: 00$ \\
\hline & Yes & 25 & 4 & $(1.64,14.10)$ & $4.3(1.21,15.56)^{*}$ \\
\hline
\end{tabular}

Significant association (* P-value $<0.05$ ** P-value $<0.01$ and ${ }^{* *}$ P-value $<0.001$ ), $n=$ sample size P-value for Hosmer and Lemeshew test $=0.56$ common mental disorder

\section{Discussion}

In the current study, the prevalence of common mental disorders and its possible association with various factors was assessed. The results showed that a remarkable proportion of prisoners had common mental disorders. The prevalence of CMDs among prisoners was found to be $58.4 \%$. Regarding prevalence, our result is consistent with those of other studies carried out in South Africa, Nigeria, Zambia, Brazil, and Iran where it was estimated at $55.4 \%, 57 \%, 63.1 \%, 56.1 \%$, and $57 \%$, respectively [9, 19-22].

On the other hand, our finding far higher than those of studies did in two areas of Ethiopia, Kenya, and Iran and reported $35.5,50,28.9$, and $43.4 \%$, respectively $[8,14$, $16,23]$. The variation might be due to distinctions in the sample sizes, measurement tools, and the socio-culture distinctions between Ethiopia and the other counties.

In Dilla (south Ethiopia), Jimma (southwest Ethiopia), and Iran, a clinical outcomes, and the symptoms check list-90-revised questionnaire were utilized to screen and assess CMDs among prisoners, respectively $[8,14,16]$. On top of that, crime type and length of sentences could be considered as sources of variations.

The present study finding was lower than those of studies done in Egypt, the United States, South Wales, Australia, Iran, and Pakistan where the magnitude was estimated at $81.5 \%, 70 \%, 74 \%, 80 \%, 88 \%$, and $85 \%$, respectively [12, 20, 24-27]. The discrepancy might be due to measurement tools and sample sizes. In Egypt, 88 prisoners were included in the study to assess depression and anxiety disorders [12]. In Australian, 916 prisoners were studied using the Composite International Diagnostic Interview (CIDI) to test psychiatric illnesses [25], but in the US taking the global severity index of the brief symptom inventory was employed to assess psychiatric disorders [21]. More than twice as many participants of the current study were enrolled in South Wales to assess common mental illnesses by using CIDI among prisoners [20]. In Iran, the fourth edition of the diagnostic and statistical manual criteria was put to use to assess a lifetime diagnosis of psychiatric disorders among prisoners [22], and in Pakistan the beck depression inventory scale was used to test depression in people [24].

Regarding factors, CMDs were 2.3 times higher among respondents who had secondary school education compared to prisoners who had above tertiary level education. This finding supported by that of study done in the southern parts of Ethiopia [14].

Poor social support was 2.4 times more likely to develop CMD compared with good social support. The reason might be that poor social support is one cause of mental illness which affects the treatment outcomes of the problem.

Economic crises in the last 6 months were three times more likely to be a risk factor for CMD compared to situations with such crises. The reason might be that serious economic crises and financial problems are major socioeconomic risk factors for mental health disorders. Such crisis among prisoners contributes to declining quality of life, depression, suicide, and homicide.

Prisoners who were not employed before arrest were 1.7 times more likely to develop CMD than prisoners 
who had jobs. Unemployment is one of the factors for mental illnesses lead prisoners to CMD and repeated arrests. This finding is consistent with that of a study done in Nigeria [22].

Finally, history of psychiatric illness was 4.3 times more likely to cause CMD compared with such no history. This result is consistent with that of a study done in Egypt [12]. The reason might be that just like antisocial personality disorder, substance use disorder, and history of mental illnesses are strongly associated with criminals in that such history may aggravate CMDs during imprisonment.

\section{Conclusion}

In study, the overall magnitude of common mental disorder was $58.4 \%$. Poor social support, economic crisis in the last 6 months, history of mental illness, secondary level education, and unemployment before arrest were significantly associated with common mental disorders.

\section{Limitations}

A cross-sectional study design, we cannot permit conclusions about some variables, for example, about deciding whether common mental disorder symptoms are at risk or a consequence. This finding of this work is likely only to hint at the complex interactions between CMDs and explanatory variables. Further research should be conducted on risk factors for CMDs to strengthen and broaden our results.

\section{Additional files}

Additional file 1. Distribution of criminal and prison-related characteristics of prisoners in Addis Ababa correctional center, Addis Ababa, Ethiopia, in 2015. $(n=447)$.

Additional file 2. Prevalence of common mental disorders among prisoners in Addis Ababa correctional center, Addis Ababa, Ethiopia, in 2015. $(n=447)$.

\section{Abbreviations}

AOR: adjusted odds ratio; CMD: common mental disorders; CIDI: composite international diagnostic interview; OR: odds ratio; SRQ: Self Reporting Questionnaire; WHO: World Health Organization; UOG: University of Gondar.

\section{Acknowledgements \\ The authors acknowledge Amanuel Mental Specialized Hospital, Ethiopia, for funding the study. The authors appreciate the respective study institutions and the study participants for their cooperation in providing the information.}

\section{Authors' contributions}

AS conceived the study and involved in the study design, reviewed the article analysis, report writing and drafted the manuscript GM, and GT also involved in the study design, analysis and drafted the manuscript. All authors read and approved the final manuscript.

\section{Funding}

The study was funded by the University of Gondar and the funders only involved by giving the funding for the design of a study, data collection, analysis, and interpretation only.

\section{Availability of data and materials}

The dataset during and/or analyzed during the current study available from the corresponding author on reasonable request.

\section{Ethics approval and consent for participant data}

Ethical clearance was obtained from the Institution of Review Board of the University of Gondar and Amanuel Mental Specialized Hospital. After approval, a formal letter of permission was obtained from Amanuel Mental Specialized hospital. All prisoners were given information sheets and were included in the study only after they provided written consents. Confidentiality of information was maintained by using anonymous copies. Participants who had severe CMDs were considered for linking them with psychiatrists for further interventions and treatment.

\section{Consent for publication}

Not applicable.

\section{Competing interests}

The authors declare that they have no competing interests.

\section{Author details}

${ }^{1}$ Department of Non-communicable Diseases, Addis Ababa Correctional Institution, Addis Ababa, Ethiopia. ${ }^{2}$ Department of Psychiatry, College of Medicine and Health Sciences, University of Gondar, Gondar, Ethiopia.

Received: 15 January 2019 Accepted: 5 July 2019

Published online: 12 July 2019

\section{References}

1. WHO. The world health report 2001: new understanding, new hope. 2001.

2. Lazarus R, Freeman M. Primary-level mental health care for common mental disorder in resource-poor settings: models \& practice-a literature review. Pretoria: Sexual Violence Research Initiative, Medical Research Council; 2009.

3. Prince M, Patel V, Saxena S, Maj M, Maselko J, Phillips MR, et al. No health without mental health. Lancet. 2007;370(9590):859-77.

4. WHO. World health report: Mental health: new understanding, new hope. 2008.

5. WHO. The World health report: 2001: Mental health: new understanding, new hope. 2001.

6. Mansoor M, Perwez SK, Swamy TN, Ramaseshan H. A critical review on role of prison environment on stress and psychiatric problems among prisoners. Mediterr J Soc Sci. 2015;6(1 S1):218.

7. Armour C. Mental health in prison: a trauma perspective on importation and deprivation. Int J Criminol Sociol Theory. 2012;5(2):886-94.

8. Sepehrmanesh Z, Ahmadvand A, Akasheh G, Saei R. Prevalence of psychiatric disorders and related factors in male prisoners. Iranian Red Crescent Med J. 2014;16(1):e15205.

9. Ahmad A, Mazlan NH. Stress and depression: a comparison study between men and women inmates in Peninsular Malaysia. Int J Hum Soc Sci. 2014;4(2):153.

10. Naidoo S, Mkize D. Prevalence of mental disorders in a prison population in Durban, South Africa. Afr J Psychiatry. 2012;15:30-5.

11. Seena F, Adrian JH, Katrina B, Massimo C, Robert T. The mental health of prisoners: a review of prevalence, adverse outcomes and interventions. Lancet Psychiatry. 2016;3:871-81.

12. Ibrahim EM, Halim ZA, Wahab EA, Sabry NA. Psychiatric morbidity among prisoners in Egypt. World J Med Sci. 2014;11(2):228-32.

13. Janet CB, Tigran A, Andrea KF, Joel R, Steven MA, Natalya CM, et al. Prevalence of mental health disorders among justice-involved veterans. Epidemiol Rev. 2015;37:163-76. 
14. Gemeda TT. Prevalence and predictors of psycho-pathological symptoms among inmates in Dilla Correction Center, SNNPR, Ethiopia. Int J Crim Just Sci. 2014;9(1):110-21.

15. Briefing 39:Mental health care and the criminal justice system. London. 2009

16. Audu M, Tesfaye M, Gurmu S, Mela M. Lifetime prevalence of substance abuse and mental distress among homicide offenders in Jimma prison, Ethiopia. Afr J Appl Psychol. 2008;2(3):15-26.

17. Kortman FHS. A compression and motivation in responses to psychiatric screening instrument validity of the SRQ in Ethiopia. Br J Psychiatry. 1988;153:95-101.

18. Bøen $\mathrm{H}$. Characteristics of senior centre users- and the impact of a group programme on social support and late-life depression. Norsk Epidemiol. 2012;22(2):261-9.

19. Andreoli SB, dos Santos MM, Quintana MI, Ribeiro WS, Blay SL, Taborda JG, de Jesus Mari J. Prevalence of mental disorders among prisoners in the State of Sao Paulo, Brazil. PLoS One. 2014;9(2):e88836.

20. Tony B, Allnutt S. Mental illness among new south wales' prisoners. In: Service NCH, editor. Australia. 2003.

21. Popa C. Mental health in Romanian prisons. Probation Junior. 2009;1(1):82-107
22. Armiya'u AY, Obembe A, Audu MD, Afolaranmi TO. Prevalence of psychiatric morbidity among inmates in Jos maximum security prison. 2013.

23. Crisanti AS, Frueh BC. Risk of trauma exposure among persons with mental illness in jails and prisons: what do we really know? Curr Opin Psychiatry. 2011;24(5):431-5.

24. Shahid I, Aftab MA, Yousaf Z, Naqvi SH, Hashmi AM. Prevalence of depression among male prisoners at an Urban Jail in Pakistan. HealthMED. 2014;8:699.

25. Butler T, Andrews G, Allnutt S, Sakashita C, Smith NE, Basson J. Mental disorders in Australian prisoners: a comparison with a community sample. Aust N Z J Psychiatry. 2006;40(3):272-6.

26. Kane M, DiBartolo M. Complex physical and mental health needs of rural incarcerated women. Issues Men Health Nurs. 2002;23(3):209-29.

27. Seyed MA, Maryam N, Mahdi P, Omid Y, Shahrokh A, Seyed VS, et al. Psychiatricmorbidity among sentenced prisoners: prevalence study in Iran. Br J Psychiatry. 2006;188:159-64.

\section{Publisher's Note}

Springer Nature remains neutral with regard to jurisdictional claims in published maps and institutional affiliations.
Ready to submit your research? Choose BMC and benefit from:

- fast, convenient online submission

- thorough peer review by experienced researchers in your field

- rapid publication on acceptance

- support for research data, including large and complex data types

- gold Open Access which fosters wider collaboration and increased citations

- maximum visibility for your research: over 100M website views per year

At BMC, research is always in progress.

Learn more biomedcentral.com/submissions 